\title{
Enhancing Adult Learners' Motivation for Learning English Grammar through Language Games
}

\author{
* Dr. Syed Shujaat Ali, Chairman / Assistant Professor (Corresponding Author) \\ ** Muhammad Waqar Ali, Lecturer \\ *** Tariq Amin, Visiting Lecturer
}

\begin{abstract}
Grammar, although indispensable for successful communication, is always a dry subject for most learners and needs a high motivation for learning. Motivating language learners for learning grammar of English in Pakistan has always been a challenging task for the language instructors. This study investigated whether language games motivate adult learners for learning grammar or not. Language games were adopted as a motivational strategy for teaching English grammar to a sample of 31 male and 19 female first-year undergraduates of Islamia College Peshawar, who were not studying English as a major subject; their ages ranged between 19 to 22 years and they spoke Pashto as mother tongue. After teaching them grammar for one semester, the instructors-the researchers themselves-sought their feedback on the use of games through a 25-item questionnaire comprising sub-sets such as interest, satisfaction, effort, tension, choice, usefulness, competition, and pre- and post-treatment experience of learning grammar. The findings of the study manifest that language games motivate not only young learners but also adult language learners. It was suggested that teaching-learning activity based on games should be made an integral part of the course of students of primary and high schools, in addition to being made a part of the primary and high school teacher education.
\end{abstract}

Keywords: $\quad$ Motivation, Adult Learners, Language Games, Grammar Learning Introduction

Motivational paucity is one of the major concerns of language classrooms in Pakistan. This problem is not limited to young learners only; instead, language learners at universities also find themselves unmotivated in the language classroom (Ali, 2016). Two of the researchers have studied and taught at Islamia College University, Peshawar, while the two have only been students at this university. Taking admission in Islamia College University remains the first choice of most students from all over the province. Therefore, from all over the province only very highly competent students with high marks make up to Islamia College Peshawar. The researchers felt that even them as students and then through their feedback as teachers, have found a lack of motivation among highly competent students at this university for learning English grammar. Reasons for their lack of interest in learning language and particularly grammar may be caused by their intent, pedagogic content, teaching practices, and so on. Sometimes students do not feel any need for English in a subject. For instance, the researchers have heard this question many a time from the learners: what is the need of English grammar in BS Physics, or BS Chemistry?

At times, language instruction itself becomes monotonous for learners, particularly when instruction is based on teaching grammar rules only without relating it to authentic content. Lastly, students may not find the teacher's methodology interesting. The lack of motivation, therefore, causes numerous hindrances for language instructors to achieve pedagogic objectives in the language classroom. Even it becomes a challenge at times for the teacher to convince the learners of the importance of learning grammar for their respective disciplines.

\footnotetext{
* Department of English, Kohat University of Science \& Technology, Kohat

Email: s_shojaat_ali@yahoo.com

** Department of English, Islamia College University, Peshawar Email: waqarali@icp.edu.pk

*** Department of English, Kohat University of Science \& Technology, Kohat

Email: tariq.ktk.733@gmail.com
} 
Ali (2016) has categorized the learners into three types concerning motivation: (1) highly motivated; (2) less motivated; and (3) unmotivated. The first type of learner takes interest in learning English without any hesitation. The second category learners are a bit reluctant in learning Englishtheir reluctance may be caused by any factor. Learners of the last type do not want to learn English at all. This study deals with the second and third types of learners, focusing on the pedagogic approach towards teaching English grammar.

\section{Objective of the Study}

To investigates whether language games enhance the motivation level of the undergraduate learners for learning the English language.

\section{Literature Review}

Motivation is a matter of concern across many disciplines; nevertheless, educational psychology dissects motivation into personal, cognitive, and affective factors about learners' psychology. Motivation is primarily an intra-cognitive process that assists individuals in satiating their wants. Some psychologists and applied linguists have studied the concept of motivation in the language learning process, measuring learners' language attitude (Gardner, 1985). Gardner (1985) defines motivation as an admixture of desire and struggle for gaining a goal; it provides the individual with rationale for factional struggle to achieve a target. It embodies the attitude, desire, and struggle for language learning. Agreeing with him, Johnson and Johnson liken motivation to a "driving force" which moves one to their desired goals (2003, p. 17). Williams and Burden (1997) have similar opinion in this regard. They view as a "cognitive and emotional arousal", leading to conscious choice of behavior and insistent "intellectual and/or physical effort" (1997, p. 120). All the above-mentioned definitions highlight two key factors - desire and effort - concerning the phenomenon. The definitions reflect both behaviourist and cognitivist school of thought. Regarding motivation, the former group considers the external factors essential for a behavior, whereas the latter school deals with it from a cognitive perspective since its interest is in identifying factors influencing people's choice of different options. Such a dyadic approach has led to classificatory dichotomy of the phenomenon: intrinsic and extrinsic motivation.

Various studies have investigated motivation as a psychological factor in learning English as a foreign language. And different theories have classified the concept differently. For instance, selfdetermination theory categorizes motivation as extrinsic and intrinsic motivation (Deci \& Ryan, 1995). The learners endowed with intrinsic motivation, participate in a task for its own sake, not for any external or material benefit. They find the activity itself pleasurable or useful. On the contrary, the externally motivated students perform in a task for some external benefit such as passing an exam, getting a prize, or else. Brown (2007) supports the first type of motivation-intrinsic motivation-for teaching a language. The intrinsic motivation emerges from within the learners, while the extrinsic one is caused by external factors.

Relating the concept of motivation to language learning, Mc Groarty (1996) categorizes the concept differently: instrumental and integrative motivation. The former entails that one learns language for some external benefits like getting through an exam or achieving some professional goal. Conversely, the latter refers to one's desire to learn the language to interact with the speakers of the target language and to be liked by them. An instrumentally motivated learner may learn English as a requirement for the degree, for improving communication skills to get a job, understanding other subjects, or any other reason, but not for its own sake or its culture. On the other hand, the learners endowed with integrative motivation will learn English for its own sake due to their interest in the target language and its culture. They may want to immigrate to the target country and integrate with its culture and people.

Many believe that motivation is essential for learning grammar (Pinheiro, 1996; Thornbury, 1999). Though the emergence of the communicative approach in language pedagogy undermined the importance of grammar in learning language, a microscopic analysis of the syllabi appeared in the 1970s reflects that they were primarily based on grammar (Thornbury, 1999). Attention, understanding, and memory are the three prerequisites of developing grammatical competence. He argues that motivation and learning grammar are inseparably linked, and lack of motivation will lead to inefficacy of the three conditions: attention, understanding, and memory. Therefore, the teacher is required to shoulder the responsibility of designing such task that not only arouse their interest but also achieve the pedagogic goals. Pinheiro (1996) also asserts that motivation is indispensably 
required for enhancing knowledge of grammar. She believes that students should be highly motivated to learn the grammar of a language. Besides, she has suggested some instructional strategies for teaching grammar.

Researchers have identified different factors that impinge on the motivation level of language learners. The effect(s) may be positive or negative. For instance, Rivers (1983) underscores some factors like anxiety, fear, social status, and social approval. Simply, learners' fear of failure may lead them to perform well or badly. Also, Williams \& Burden (1997) have identified another condition called "learned helplessness" wherein the learner believes that intelligence or competence is fixed and cannot be improved. Such a deterministic view of learning may convince them of their inability to improve their knowledge of grammar. This may affect motivation levels negatively. Lightbown and Spada's (2006) notion of partial motivation is also worth mentioning. They inferred from various studies conducted to investigate the phenomenon of motivation in language learning, that learners may be more motivated in some areas of language learning than others. For instance, they found that in some studies learners were more motivated in oral communication skills than in learning grammar. In short, lowering the affective filter of the learners will result in enhancing their motivation for language/grammar learning.

That said, the next concern is how to enhance the motivation of the learners for learning grammar. Regarding the concern, Nunan (1991) acknowledges the absence of any universal method for motivating language learners. The reason is that language pedagogy and classroom dynamics are always in flux; therefore, agreement upon a single method in this regard seems an obvious impossibility. However, different instructional strategies have been proposed for the said purpose. One of such strategies is language games. This study focuses on language games as a motivational strategy for learning/teaching grammar of English.

Various studies have found that language games motivate learners in learning a language. For example, Khonmuhammad, Gorjian, and Eskandari (2014) articulate that language games stimulate reluctant learners to partake in the language learning process. The games ensure agility, robustness, and self-direction in such learners. In like manner, Wierus and Wierus (1994) contend that games characterize the learning environment with relaxation which encourages the learners to collaborate in an entertaining milieu and expedites their learning. Adding to it, Wright (1990) proclaims that language games create an ambiance of success for novices. McCallum (1980) underscores the importance of games in the words: "games automatically stimulate student's interest, a properly introduced game can be one of the highest motivating techniques" (as cited in (Khonmuhammad, Gorjian, \& Eskandari, 2014, p. 331).

Khan (1991), agreeing with McCallum, asserts that the use of games is effective teaching language for they motivate the learners. However, his study is different than this one because the population for his study was young learners, whereas this study is conducted on adult learners. A sense of competition is another indirect repercussion of language game (Avedon as cited in Deesri, 2002). Being motivated, the learners want to compete and win the game. Uberman (1998) supports Avedon's stance due to her personal pedagogic experience. She observed that games stimulated her learners because they found the classroom practice of language lessons very entertaining.

A gap can be identified in the literature on the effectiveness of language games as a motivational strategy for teaching grammar since most of the abovementioned studies dealt with language in general (Wright, 1990; Wierus \& Wierus, 1994) or teaching of vocabulary (Uberman, 1998), not the grammar of the language particularly. Next, there is a gap for the population as well. The studies were conducted either on young learners or teenagers (Khonmuhammad, Gorjian, \& Eskandari, 2014), not on post-teenage or adult learners. Lastly, the context also changes in the current study. The current study intends to investigate whether language games motivate undergraduate learners of English to learn grammar in Pakistan and to confirm whether the findings of the study agree or disagree with those of the previous studies on the matter under discussion.

\section{Methodology}

The study is a quantitative inquiry as suggested by Dorneyi (2007) for ensuring objectivity in research. He remarks that quantitative research guarantees the reliability of findings and reduces the researcher bias. Manipulation and misinterpretation of data are next to impossible in such studies (Levon, 2010). Quantitative investigation entails the application of statistics in the collection, classification, and examination of data. 
The sample of the study comprised of 50 undergraduate students at Islamia College Peshawar, Pakistan. Following a convenient sampling technique, the researcher selected a class of non-English major students. The sample included 31 male and 19 female students. The age of the learner varied from 19 to 22 years, and all of them spoke Pashto as mother tongue. The sample was treated as an experiment group. The treatment was based on teaching grammar through language games to enhance the learners' motivation for learning grammar. Language games such as "Basta" (Leslie, 2011), "Guess the Sport," "Sprinkling of People" (Rinvolucri, 1990), "Let's Go Camping" (Belisle, 2004) and many more were used at the practice stage during lessons.

A 25-item questionnaire was administered after the treatment to collect data. A five-point Likert scale was used in the questionnaire. The scale sought responses against the following categories: strongly agree, agree, undecided, disagree, and strongly disagree. The questionnaire included two sections: the first section sought demographic information about the participants, and the second section required responses for measuring the learners' motivation.

The items of the questionnaire were organized under eight themes: interest, perceived competence, effort, tension, perceived choice, usefulness, sense of competition, and previous experience. The first two statements measured whether they enjoyed the learning process and how much (Q1-2). The next two statements (Q3-4) dealt with the learners' perception of their grammatical competence after playing language games. Statement 5 and 6 sought responses to measure how much effort or importance they associate with games. Level tension/pressure was gauged in the next two statements (Q7-8). Similarly, statements 9 and 10 scaled their perception of choice. Two more themes, namely, the usefulness of games and a sense of competition were calibrated through statements 11 to 16 and statements 17 to 19 , respectively. The last set of six statements (Q20-25) concerned with the learners' previous experience of grammar learning. To measure the reliability of the questionnaire, a reliability test was run on SPSS and Chronbach's Alpha score of the questionnaire read as 0.955 which means the statements and findings of the instrument are reliable for inferring conclusions.

\section{Results and Discussion}

As mentioned above, the questionnaire was based on eight themes, comprising 25 statements. The questionnaire contained some negative statements to cross-check the learners' responses. The data of the study manifested that language games enhanced learners' motivation for learning grammar. The results of the inquiry are tabulated in percentage in Table 1 below and are discussed theme-wise as following.

\section{Interest}

This section included two statements: one positive and one negative. The negative statement was included to confirm whether the responses for the positive statement are given consciously. The results showed that games aroused their interest in learning grammar. A big majority (92\%) of the participants enjoyed playing game, and none cast any vote against the use of games (Table 1, S1). However, a small portion (8\%) remained neutral in expressing the opinion about their interest in games. But not a single student did disagree with the statement. Furthermore, more than half of the participants $(56 \%)$ were highly interested in playing games. Correspondingly, the next statement (Table 1, S2) provided similar results concerning enjoyment in games. All of them viewed that playing games was not monotonous. Thirty-eight (76\%) students expressed strong disagreement with the notion that playing games was monotonous. Responses to the second statement support the findings of the first statement. If the statement is paraphrased with the antonym of the word 'boring' and the responses are reversed, then the finding will read: seventy-six percent of students strongly believe that playing games is an entertaining activity in the language classroom. However, there will be still a gap of twenty percent between SA responses for the first statement and those for the second statement.

\section{i. $\quad$ Satisfaction}

Like the previous section, this part also consisted of two statements: one affirmative, one negative. The two statements scaled their satisfaction level of their grammatical competence/performance. Responding to the statement (Table 1, S3), forty-eight students (96\%) expressed their satisfaction with their performance after having been taught grammar through language games. Nonetheless, only two students gave neutral responses to the statement, but none of them disagreed with the statement. On the contrary, when asked the same thing in the opposite 
manner (Table 1, S4), they responded slightly differently. For instance, seventy-four percent of them strongly disagreed that they could not do well while playing games, and twenty-six percent only disagreed with the same statement, but none of them agreed or strongly agreed to the statement. The results of statement 4 validated those of the preceding statement. This also supports the claim that games motivate learners for learning grammar.

\section{ii. Effort}

The next set of statements (S5-6) gauged their level of effort put while participating in gameactivities. This part intended to indirectly measure the level of importance the students ascribed to language games in the context of grammar class. The results were quite encouraging for the study. The first statement (S5) in this section was phrased affirmatively and the next (S6) was worded oppositely. The latter statement (S6) phrased negatively intended to cross-check the preceding one. Overall, ninety-six percent of participants professed that they put a lot of effort while participating in the activities. Only two students remained neutral in their responses to the statement. A similar ratio of responses was observed in the next statement (S6): seventy percent of students strongly disagreed, and twenty-six percent only disagreed with not putting much energy into the tasks (language games). As in the previous statement, only two respondents remained neutral in this statement as well. Overall, a clear-cut majority (96\%) proclaimed that their level of energy was high while playing games. Moreover, not a single participant expressed a lack of energy or effort in this regard, which is evidence of their being motivated during the learning process. What is more, the results showed that they ascribed importance to language games along with grammar.

\section{iii. Tension}

The set of statements under the theme tension measured their level of nervousness and comfort in playing language games. As per earlier practice, the set included one positively structured statement and one negatively phrased sentence. The rationale behind including this theme was to confirm whether and how far the learners were contented with the idea of introducing games in grammar class. The first statement (Table 1, S7) gauged their nervousness in learning grammar through games. An overwhelming majority (98\%) expressed their disagreement with the notion of feeling tension while playing games. Only one student could not agree or disagree with the statement (S7). The findings were authenticated by the responses provided for the next statement. Like the previous statement, the statement 8 confirmed that forty-nine (98\%) participants felt relaxed while playing games. Only one student was neutral on the statement. However, none reported a sense of discomfort in playing games.

\section{iv. Choice}

The set of statements under the theme choice assessed their volition for participating in games, and the results showed that they participated willingly in the activities. One statement measured compulsion, the other quantified the level of choice. Though every learner, being a part of the class, had to participate in games, his or her responses to the next statement show that he or she was willing to participate in the games (Table 1, S10). Moreover, the first statement of the set intended to measure their responses in a hypothetical situation wherein they would be given the choice to partake in the activities. Responding to the statement (Table1, S9), fourteen (28\%) out of fifty students disagreed and thirty-six (72\%) strongly disagreed with the idea of forced participation in the games. Overall, all of them believed that they were not compelled to play the games. The next statement (S10) counter-checked the preceding one since nonappearance of compulsion necessitates the existence of choice. Responding to the statement, all students manifested their desire to play the games in grammar class. To analyze the statistics further, forty-five percent of learners agreed, and fifty-five percent strongly agreed to the statement. Nevertheless, none of the students hinted that they were forced to participate in the games. A balance was observed between the responses against the category 'agree' (45\%) and 'strongly agree' $(55 \%)$ which displayed variance in learners' perception of their desire to participate in the games. Overall, the findings strengthen the stance that language games motivate the learners.

\section{v. Usefulness}

Unlike the previous sets, this one comprises six statements (Table 1, S11-16) to assess learners' perception of the value and utility of the games, relating the notion of value to games in different ways. Generally, the leaners acknowledged the value of games for teaching/learning grammar. The majority (96\%) of them believed that games were valuable (Table1, S11). Twenty 
students agreed and twenty-three strongly agreed to the statement (S11), none either disagreed or remained neutral on this statement. Next, all the learners thought that the games assisted them in comprehending grammar (Table 1, S12). Half of them agreed and the rest strongly agreed to the statement. The next statement (S13) was related to memorizing grammar rules. Sixty-four percent of learners strongly agreed and thirty-six percent of them merely agreed to the proposition (S13). However, no response was found against the statement. Overall, all of them recognized the aptness of games in memorizing grammar rules. However, memorization in this context means more than rote learning.

Being phrased in a negative structure, the next statement (S14) double-checked the learners' responses to earlier statements (S11-12). One-fifth of the students disagree, and four-fifth strongly disagrees with the belief that games were not useful in learning grammar; however, no student either agreed or strongly agreed to the statement. In short, all the learners believed that games were not worthless. The finding confirms mostly to that of statement 11 ( $96 \%$ considered games valuable) and completely to that of statement 12 (100\% found games helpful in understanding grammar).

The learners recorded their responses to the next two statements (S14-15) in equal ratios. Twenty-two (54\%) participants strongly agreed and twenty (40\%) agreed that games improved their concentration during learning grammar, but three $(6 \%)$ students neither agreed nor disagreed with the statement. Overall, ninety-six percent of students felt their concentration increased due to language games. Similarly, fifty-four percent of students believed and forty percent of them strongly believed that the games improved their study habits. Again, three respondents remained neutral. In short, findings of all the six statements in this section strengthen the case of language games as a motivational strategy for teaching grammar.

\section{vi. Competition}

The next set of three statements (S17-19) gauged the learners' sense of competition. The idea was to measure how much the game developed a challenging environment and how far that environment succeeded in engaging them in the learning process. Though phrased differently, all three statements expressed the same idea. Therefore, the statistics display similar ratios of responses. Ninety-eight percent of the learners expressed their desire to win the game, whereas just one person remained unconcerned in this regard (Table 1, S17). But there was no response against the statement. By the same token, thirty (60\%) students strongly agreed and twenty (40\%) agreed that they struggled to be the best at playing the games (Table 1, S18). In other words, all of them tried to be the best. The next statement sought the same information negatively (S19). Ninety-six percent of them disagreed that they did not care about the first position while playing games. Only two remained neutral. The findings show that the games triggered a sense of competition in them and subsequently enhanced their motivation for learning grammar.

\section{vii. Experience of learning grammar}

This set contains six statements (Table 1, S20-25): the first three statements (S20-22) are about the previous experience of learning grammar, and the next three (S23-25) are about the current experience of learning grammar through language games. An obvious division in the findings of the two experiences has been observed. Regarding the previous experience, ninety-four percent of students professed that they did not have an enjoyable experience of learning grammar at school ([matric] Table 1, S20). The rest remained neutral on the statement. Also, forty-eight participants expressed their displeasure of grammar learning experience at college (S21). Only four percent of them remained neutral. Correspondingly, a majority confronted difficulty in learning grammar before learning it via games; on the other hand, a small portion disagreed with the statement (S22).

For the current experience of learning grammar through games, the learners manifested a positive attitude. The findings of this section show a vivid impact of the current experience on the learners' motivation level. For instance, only twenty percent of learners wanted to learn grammar before the current experience, whereas the rest eighty percent either disagreed or strongly disagreed with the statement (S23). Moreover, a vast majority (96\%) felt an increase in their desire to learn the grammar of English due to the current experience (S24). One two respondents remained neutral. Next, a similar number of students $(94 \%)$ found learning grammar via games a better way than the traditional way of rote learning of grammar rules, which are forgotten very soon.

The detailed analysis of the findings advocates the hypothesis that language games enhance learners' motivation for learning grammar. Games activated the learners during the learning process. 
Besides, the learners took interest in learning grammar via games. The findings of this section are in line with those of Khan (1991) and Khonmuhammad, Gorjian, and Eskandari (2014). Both studies proclaimed that language games aroused learners' interest in learning language. However, the line of departure between the current study and the abovementioned two studies is the difference in population. Khan (1991) investigated the motivation level of young learners, whereas the current study is concerned with the undergraduates (almost adults, or at least post-teenagers). Moreover, Khnomuhammad, Gorjian, and Eskandari investigated the use of games as a motivational strategy in teaching the English language in general, but the current study narrowed the area to grammar only.

A sense of competition and challenge is also a strong source of motivation which this study created in the learners and is supported by Avedon (as cited in Deesri, 2002). Moreover, Uberman (1998) accentuates the element of fun for learning. The findings show that games entertain the learners a lot in grammar class. However, Avedon studied young learners learning language, and Uberman (1998) practices games in teaching vocabulary, whereas the current study used the games for teaching only grammar to undergraduates. Besides, Yu (2005) also supports the findings. He concluded that games motivated the German $12^{\text {th }}$-grade learners of English. The abovementioned comparisons authenticate the findings of the research. However, the line of departure is that the games were used as a motivational strategy for teaching grammar to undergraduates.

\section{Conclusion}

It may be inferred from the analysis that language games can confidently be used to motivate adult learners for learning grammar. Though it is generally assumed that adult learners are serious in terms of learning and they do not like fun in learning, yet the study supports the contrary. Moreover, the competitive environment is liked by every age group; therefore, games - having an agenda of creating a challenging milieu - prove effective in engaging the adult learners in grammar class. In like manner, games promoted a feeling of comfort and relaxation, which is a rare phenomenon in traditional grammar class. It was recommended that ELT or EFL curricula should have ample room for games so that they should be well-integrated into the curriculum of English meant for the primary and high school students. Teacher's education and their trainings should include enhancement of teachers' skills in using games for teaching English language grammar. Overall, the study is an addition to the literature available on the matter. Future researchers are encouraged to explore the matter more extensively by exploring the motivation level of both sexes separately and enlarging the sample size.

\section{References}

Ali, M. W. (2016). Effectiveness of language games in teaching grammar to undergraduates at Islamia College Peshawar. Peshawar: Department of English, Islamia College [Master Thesis].

Belisle, R. (2004, April). Activities to teach count and noncount distinction. Retrieved from The Internet TESL Journal: http://iteslj.org/Lessons/Belisle-CountAndNoncount.html

Brown, H. (2007). Principles of language learning and teaching. New York: Pearson Education Limited.

Brown, H. D., \& Lee, H. (1994). Teaching by principles: An interactive approach to language pedagogy (Vol. 1). Eaglewood Cliffs, NJ: Prentice-Hall Regents.

Deci, E., \& Ryan, R. M. (1995). Human autonomy: The basis for true self-esteem. In M. Kernes (Ed.), Efficacy, agency, and self-esteem. New York: Plenum Press.

Deesri, A. (2002, Decemeber 23). Games in the ESL and EFL class. The Internet TESL Journal, 9(9).

Dornyei, Z. (2007). Research methods in applied linguistics: Quantitative, qualitative, and mixed methodologies. Oxford: Oxford University Press.

Gardner, R. (1985). Social psychology and second language learning: The role of attitudes and motivation. London: Edward Arnold Ltd.

Johnson, K., \& Johnson, H. (Eds.). (2003). Encyclopedic dictionary of applied linguistics: A handbook for language teaching. Blackwell Publishers.

Khan, J. (1991). Using games in teaching English to young learners. In C. M. C. Brumfit, \& R. Tongue (Eds.), Teaching English to children: From practice to principle (pp. 42-143). London: Longman.

Khonmuhammad, H., Gorjian, B., \& Eskandari, Z. (2014, March). Using games to affect learners' motivation in learning English grammar. International Journal of Language Learning and Applied Linguistics World, 5(3), 325-341. 
Leslie, L. (2011, June 10). A fun language game for older kids and adults. Retrieved from Multicultural familia: http://www.multiculturalfamilia.com/2011/06/10/a-fun-language-gamefor-older-kids-and-adults/\#ixzz260GsjXcY

Levon, E. (2010). Organizing and processing your data: The nuts and bolts of quantitative analyses. In L. Litosseliti (Ed.), Research methods in linguistics (pp. 68-92). London: Continuum International Publishing Group.

Lightbown, P. M., \& Spada, N. (2006). How languages are learned. Oxford: Oxford University Press. Pinheiro, F. (1996). Designing a writing component for teen courses at a Brazilian language institute. In F. Pinheiro, Teachers as Course Developers. Cambridge: Cambridge University Press.

Rinvolucri, M. (1990). Grammar Games: Cognitive, affective and drama activities for EFL learners. Cambridge: Cambridge University Press.

Rivers, W. (1979/1983). Linguistics and language teaching. A Forum Anthology, 3-11.

Uberman, A. (1998). The use of games for vocabulary presentation and revision. Forum, 36(1), pp. 20-27.

Wierus, B., \& Wierus, M. (1994). Games in learner-based teaching. Oxford: Oxford University Press.

Williams, M., \& Burden, R. (1997). Psychology for language teachers. London: Cambridge University Press.

Wright, A. (1990). Games for language learning. Cambridge: Cambridge University Press.

$\mathrm{Yu}, \mathrm{S}$.-y. (2005). The effects of games on the acquisition of some grammatical features of L2 German on student's motivation and on classroom atmosphere. Ph.D. Thesis, Australian Catholic University, Faculty of Education, Victoria. 